\title{
Comparative Study of Some Potential Paracrine Factors Produced by Normal and Androgenetic Alopecia Hair Follicles
}

\author{
Saeed A. Alwaleedi* \\ Biology Department, Faculty of Science, Taif University (TU), Taif, Saudi Arabia \\ *Corresponding author: swaleedi@hotmail.com
}

Received February 10, 2015; Revised February 19, 2015; Accepted February 26, 2015

\begin{abstract}
Androgens are the main regulators of human hair growth. Paradoxically, androgens can convert small vellus hair follicles to long terminal ones as seen during growth of beard and in hirsutism, however they also can stimulate the gradual transformation of large terminal scalp follicles to tiny vellus ones causing androgenetic alopecia in individuals with a genetic predisposition. Hair disorders are poorly controlled and may cause psychological distress and reduction in the quality of life. The molecular mechanisms of androgen action in human hair follicles are not fully understood. However it is believed that androgens exert their effects on hair follicles via the dermal papilla cells by altering the regulatory paracrine factors produced by the dermal papilla itself and affect the other follicular components. The study aimed to identify key paracrine factors which involved in androgenregulated alopecia. Balding and non-balding scalp hair follicles isolated and analyzed by molecular biological methods, DNA microarray and quantitative real-time PCR. Comparing balding and non-balding follicles from the same individuals revealed the expected reduction in several keratin and keratin-related protein genes supporting this approach's validity. There were also significant differences in paracrine factors previously implicated in androgen action by in vitro studies. Several factors believed to increase during androgen stimulation of larger, darker follicles, e.g. IGF-I and SCF, and VEGV were lowered in balding follicles, while putative inhibitory factors, e.g. TGFß-1, IL$1 \beta$, IL-1 $\alpha$, and IL- 6 were increased. These findings increase our understanding of androgen action in human hair follicles; this could lead to better treatments for hair disorders.
\end{abstract}

Keywords: hair follicles, androgen, androgenetic alopecia, PCR, microarray

Cite This Article: Saeed A. Alwaleedi, "Comparative Study of Some Potential Paracrine Factors Produced by Normal and Rogenetic Alopecia Hair Follicles.” American Journal of Medical and Biological Research, vol. 3, no. 1 (2015): 38-47. doi: 10.12691/ajmbr-3-1-3.

\section{Introduction}

Androgenetic alopecia is a common type of hair loss. It is also called common baldness or male pattern baldness which mainly affect men [1], but can also affect women [2]. This type of hair disorder is characterised by the gradual transformation of thick, pigmented hairs on the scalp to short, thin pale hairs, in both men and women [3]. In androgenetic alopecia and also during puberty, the gradual changes in the type of hair produced by the hair follicles are related to changes in the stages of the hair growth cycle [4]. Therefore, during the disorder progression, the anagen phase of hair growth cycle shortens whereas the telogen phase remains constant [5]. There are two main factors involved in the pathogenesis of androgenetic alopecia including androgen and genetic predisposition. There is a great deal of evidence to support the involvement of androgen in the development of androgenetic alopecia. For example, androgenetic alopecia does not occur in male castrated prior to puberty and progression is stopped if postpubertal males are castrated
[6]. In castrated men, hair loss can be stimulated using testosterone replacement therapy, however withdrawal of the hormone led to a cessation in hair loss progression [7]. The role of androgen in hair loss is confirmed by the absence of androgenetic alopecia in people with complete androgen insensitivity syndrome in which individuals lack functional androgen receptors [8]. In balding men, testosterone levels are normal $[9,10]$ and the response to androgen seems to be intrinsic to the hair follicle [3]. Genetic predisposition is required for the onset of alopecia alongside androgen [11,12]. Androgenetic alopecia has been described as an autosomal dominant trait with variable penetrance [13]. A number of genes have been investigated for an association with androgenetic alopecia, it has been reported that male-pattern baldness associated with genetic variants in the androgen receptor gene $[14,15]$. In addition, recent studies showed susceptibility variants for androgenetic alopecia on chromosome 20p11 $[16,17]$. This indicates that the inheritance pattern of androgenetic alopecia seems to be polygenic.

The molecular mechanisms involved in the control of hair growth are not well understood. Androgens are the 
major regulating hormones of human hair growth. It is believed that androgens act on the hair follicle via the mesenchyme-derived dermal papilla which interprets the response indirectly for the other follicular components. The current hypothesis of androgen action in hair follicles was proposed by $[18,19]$. This hypothesis proposed that circulating androgens enter the dermal papilla via its welldeveloped blood supply. Within the dermal papilla cells of androgen dependent hair follicles, androgens bind to specific intracellular androgen receptors and then cause alteration in their production of paracrine factors. These factors then act on other components of the hair follicles, altering the type of hair produced. The identification of paracrine factors produced by dermal papilla cells in androgen dependent follicles has been the focus of much research. A number of growth factors and cytokines have been implicated in the regulation of the hair follicle $[20,21,22]$. Only some of these have been implicated in androgen action so far, generally by studying cultured dermal papilla cells; the main ones include: Insulin-like growth factor-I (IGF-I), Stem cell factor (SCF), Vascular endothelial growth factor (VEGF), Transforming growth factor- $\beta 1$ (TGF- $\beta 1$ ), Interleukin-1ß (IL-1ß), Interleukin-1 $\alpha$ (IL-1 $\alpha$ ), and Interleukin-6 (IL-6). Better understanding of these factors should elucidate androgen action in hair follicles and therefore lead to the development of treatments for androgen dependent hair disorders such as androgenetic alopecia and hirsutism.

\section{Materials and Methods}

\subsection{Skin Samples}

Human scalp skin from occipital and frontal regions of balding individuals were obtained from healthy donors as a result of routine cosmetic dermatological surgeries, with full donor consent. Tissues were collected from three healthy men (aged 51, 56 and 55 yr) with androgenetic alopecia (male pattern baldness), which was classified as class IV according to the Hamilton classification [23]. Samples were collected as full depth skin of about $0.2 \mathrm{~cm}^{2}$. Tissues were transferred to $50 \mathrm{ml}$ falcon tubes containing $30 \mathrm{ml}$ RNA stabilisation reagent, RNAlater (SigmaAldrich Ltd., UK). The samples were stored in the fridge at $4^{\circ} \mathrm{C}$ overnight to allow the RNAlater to penetrate the tissues.

Anagen hair follicles were microdissected from two areas of the scalp from each individual, frontal scalp for the balding follicles and occipital scalp for the control, non-balding ones, under a leica MZ8 dissecting microscope (Wetzlar, Germany). Isolation of balding follicles was very time-consuming and needed much care and patience due to their small size and pale colour. Each skin sample was transferred to a petri dish containing RNAlater. The skin sample was cut at the junction between the epidermis and dermis using a sterile scalpel blade. The hair follicles were pulled from the skin gently using fine forceps and then transferred into another petri dish containing fresh RNAlater kept on ice. The isolated hair follicles were cleaned of any dermis or fat debris under a higher magnification using sterile syringe needles (27G1/2 tuberculin syringe; Sigma).

\subsection{Total RNA Isolation}

Following dissection of the required number of hair follicles, the process of total RNA isolation was carried out in accordance to the manufacturer's instructions using the RNeasy Mini kit (Qiagen Ltd, Sussex, UK). The extraction process was performed in an area cleaned before use with $70 \%(\mathrm{v} / \mathrm{v})$ ethanol and RNase Zap solution (Sigma). The quality and integrity of total RNA was checked using the Agilent 2100 Bioanalyzer (Agilent Technologies, Santa Clara, USA) which uses a fluorescent assay involving electrophoretic separation to evaluate RNA samples qualitatively.

\subsection{DNA Microarray Procedure}

The Ambion WT expression kit (Ambion, Austin, USA) was used to prepare RNA samples for microarray analysis. This kit was designed to generate amplified sense-strand DNA without bias. The procedure was performed, according to the manufacturer's instruction, in the following successive steps:

First-strand cDNA synthesis: The first-strand master mix was prepared in a sterile tube $(0.5 \mathrm{ml})$ by combining the first-strand buffer mix $(4 \mu \mathrm{l})$ with the first-strand enzyme mix $(1 \mu \mathrm{l})$ at room temperature. The contents were mixed thoroughly by gently vortexing and centrifuged briefly at $8000 \mathrm{~g}$ for about 5 seconds to collect the mix at the bottom of the tube. The master mix ( $5 \mu \mathrm{l})$ was transferred to a PCR reaction tube. The total RNA sample $(5 \mu \mathrm{l})$ was added to the mix and the tube was centrifuged briefly at $8000 \mathrm{~g}$ for a few seconds. The tube was incubated in a thermal cycler for 1 hour at $25^{\circ} \mathrm{C}$, for 1 hour at $42^{\circ} \mathrm{C}$ and for 2 minutes at $4^{\circ} \mathrm{C}$. The tube was centrifuged briefly and placed in ice for 2 minutes.

Second-strand cDNA synthesis: In a nuclease-free tube, the second-strand cDNA master mix (50 $\mu \mathrm{l})$ was prepared by combining nuclease-free water (32.5 $\mu \mathrm{l})$, second-strand buffer mix $(12.5 \mu \mathrm{l})$ and second-strand enzyme mix $(5 \mu \mathrm{l})$. The tube was mixed thoroughly and centrifuged briefly. The master $\operatorname{mix}(50 \mu \mathrm{l})$ was transferred to a reaction tube containing $10 \mu \mathrm{l}$ of the resulting first-strand cDNA from the previous step. The tube was incubated in a thermal cycler for 60 minutes at $16^{\circ} \mathrm{C}$, for 10 minutes at $65^{\circ} \mathrm{C}$ and for at least 2 minutes at $4^{\circ} \mathrm{C}$. The tube was centrifuged at $8000 \mathrm{~g}$ for 5 seconds and placed in ice.

cRNA synthesis by in vitro transcription: cRNA was synthesized and amplified by in vitro transcription (IVT) of the second-strand cDNA template using T7 RNA polymerase. At room temperature, the IVT master mix was prepared by adding $24 \mu \mathrm{l}$ of IVT buffer mix to $6 \mu \mathrm{l}$ of IVT enzyme mix in a nuclease-free tube. The tube was mixed and spun down briefly for few seconds. The total volume of master mix (30 $\mu \mathrm{l})$ was added to $60 \mu \mathrm{l}$ of second-strand cDNA and mixed thoroughly by vortexing before centrifuging briefly at $8000 \mathrm{~g}$. The tube was incubated in a thermal cycler for $16 \mathrm{hr}$ at $40^{\circ} \mathrm{C}$ and then overnight at $4^{\circ} \mathrm{C}$. The resulting cRNA was purified to improve its stability and to remove any unicorporated nucleotides, salts and inorganic phosphate.

2nd cycle cDNA synthesis: Sense-strand cDNA was synthesized by the reverse transcription of cRNA using random primers. The cRNA $(10 \mu \mathrm{g} ; 22 \mu \mathrm{l})$ was combined with $2 \mu \mathrm{l}$ random primers and mixed thoroughly by gently 
vortexing and centrifuging at $8000 \mathrm{~g}$ for 5 seconds to collect the reaction mix at the bottom of the tube. The tube was then incubated in a thermal cycler for 5 minutes at $70^{\circ} \mathrm{C}, 5$ minutes at $25^{\circ} \mathrm{C}$, and then 2 minutes at $4^{\circ} \mathrm{C}$. In a nuclease-free tube, the 2nd-cycle master mix was prepared from 2nd-cycle buffer mix $(8 \mu \mathrm{l})$ and 2nd-cycle enzyme mix $(8 \mu \mathrm{l})$, and then added to $24 \mu \mathrm{l}$ of cRNA/random primer sample. The reaction mixture was incubated in a thermal cycler for 10 minutes at $25^{\circ} \mathrm{C}, 90$ minutes at $42^{\circ} \mathrm{C}$, 10 minutes at $70^{\circ} \mathrm{C}$, and for at least 2 minutes at $4^{\circ} \mathrm{C}$. After incubation, the tube was placed in ice and used for subsequent steps. On ice, RNase $\mathrm{H}(2 \mu \mathrm{l})$ was added to the 2nd-cycle cDNA to degrade the cRNA, leaving only the single-strand cDNA. After mixing by pipetting, the tube was incubated in a thermal cycler for 45 minutes at $37^{\circ} \mathrm{C}$, 5 minutes at $95^{\circ} \mathrm{C}$, and for at least 2 minutes at $4^{\circ} \mathrm{C}$. The resulting 2nd-cycle cDNA was purified to remove unincorporated dNTPs, salts and enzymes.

Fragmentation \& labeling: This process was carried out using the GeneChip terminal labelling and hybridization kit (Affymetrix, UK). The fragmentation master mix was prepared by combining RNase-free water $(10 \mu \mathrm{l}), 10 \mathrm{X}$ cDNA fragmentation buffer $(4.8 \mu \mathrm{l})$, uracilDNA glycosylase (UDG) $(1 \mu \mathrm{l})$ and apurinic/apyrimidinic endonuclease 1 (APE1) $(1 \mu \mathrm{l})$ to recognize and fragment the cDNA at dUTP residues. The prepared master mix was then added to the sample tube which contained singlestrand DNA $(5.5 \mu \mathrm{g})$ and RNase-free water (31.2 $\mu \mathrm{l})$. The reaction mixture was vortexed gently, and spun down at $8000 \mathrm{~g}$ for a few seconds and then incubated in the thermal cycler for 60 minutes at $37^{\circ} \mathrm{C}$, for 2 minutes at $93^{\circ} \mathrm{C}$, and then for 2 minutes at $4^{\circ} \mathrm{C}$. Following this incubation, labeling of fragmented single-strand DNA was performed. The labeling reaction mixture contained $5 \mathrm{X}$ TdT buffer (12 $\mu$ l, 50 mM Sodium Cacodylate, $\mathrm{pH}$ 6.8, 5 mM Cobalt Chloride and 0.5 mM DTT), deoxynucleotidyl transferase (TdT) $(2 \mu \mathrm{l})$ and DNA labeling reagent contained Allonamid triphosphate $(1 \mu \mathrm{l})$ to give the total volume $15 \mu$ l which added to the fragmented single-strand DNA $(45 \mu \mathrm{l})$. The tube was incubated in the thermal cycler for 60 minutes at $37^{\circ} \mathrm{C}, 10$ minutes at $70^{\circ} \mathrm{C}$, and then for at least 2 minutes at $4^{\circ} \mathrm{C}$.

Hybridization: The hybridization process was carried out using the GeneChip hybridization, wash and stain kit (Affymetrix). In a $1.5 \mathrm{ml}$ RNase-free eppendorf tube, the hybridization cocktail was prepared by combining $60 \mu \mathrm{l}$ of the fragmented and labeled DNA, 3.7 $\mu$ l of control oligonucleotide B2 (3nM), $11 \mu \mathrm{l}$ of 20X eukaryotic hybridization control, $110 \mu \mathrm{l}$ of $2 \mathrm{X}$ hybridization mix, $15.4 \mu \mathrm{l}$ DMSO, and nuclease-free water $(220 \mu \mathrm{l})$. The tube was vortexed gently and spun down for few seconds. The hybridization cocktail was heated at $99^{\circ} \mathrm{C}$ for 5 minutes and cooled to $42^{\circ} \mathrm{C}$ for 5 minutes, and then centrifuged at 12,000 g for about 1 minute. The GeneChip Human Exon 1.0 ST Array (Affymetrix) was equilibrated to room temperature immediately before use. The array was labelled with the name of the sample to be hybridized. An appropriate amount of hybridization mix was then injected into the array through one of its septa. The array was placed in a $45^{\circ} \mathrm{C}$ hybridization oven at $60 \mathrm{rpm}$ and incubated for about 17 hours.

Washing, staining \& scanning: After 17 hours of hybridization, the array was removed from the hybridization oven. Wash and stain steps were carried out using the GeneChip hybridization, wash and stain kit (Affymetrix). The probe array was vented by inserting a clean pipette tip into one of the septa and the hybridization cocktail was extracted using a pipettor through the other septum. The array was refilled completely with a suitable volume of wash buffer A (6X SSPE, 0.01\% Tween-20). The staining reagents consisted of streptavidin phycoerythrin (SAPE) solution and antibody solution. The SAPE solution mix was prepared by combining: $1 \mathrm{X}$ stain buffer (600 $\mu \mathrm{l}, 10 \mathrm{mM}$ MES, $0.1 \mathrm{M} \mathrm{NaCl}, 0.01 \%$ Tween20), $2 \mathrm{mg} / \mathrm{ml}$ of BSA $(48 \mu \mathrm{l}), 10 \mu \mathrm{g} / \mathrm{ml}$ of streptavidin phycoerythrin (SAPE) $(12 \mu \mathrm{l})$ and deionized water (540 $\mu l)$. Since SAPE is sensitive to light, it was stored in the dark at $4^{\circ} \mathrm{C}$ and wrapped with foil. The antibody solution mix consisted of $2 X$ stain buffer $(300 \mu \mathrm{l}), 2 \mathrm{mg} / \mathrm{ml}$ BSA $(24 \mu \mathrm{l}), 0.1 \mathrm{mg} / \mathrm{ml}$ goat IgG $(6 \mu \mathrm{l}), 3 \mu \mathrm{g} / \mathrm{ml}$ biotinylated antibody (3.6 $\mu \mathrm{l})$, deionized water $(266.4 \mu \mathrm{l})$. The wash and stain process was then carried out automatically in the Fluidics Station 450/250 (Affymetrix) using Affymetrix ${ }^{\circledR}$ GeneChip Command Console (AGCC) software. The intensity of the fluorescence of the array was scanned and measured using the Affymetrix ${ }^{\circledR}$ GeneChip ${ }^{\circledR}$ Scanner 3000 (Affymetrix). The laser was warmed up by turning it on at least 10 minutes prior to scanning. The scanner was controlled by the AGCC software..

Microarray data analysis: To study the changes in gene expression in balding versus non-balding scalp hair follicles, the Affymetrix GeneChip human exon 1.0 ST array containing 28,869 genes was used. A total of six chips were used in this study; one chip per sample. Following the scanning procedure, the scanned probe array image files were processed and analyzed using GeneSpring GX 11 software (Agilent technologies). The data was normalized to standard microarray data as pergene normalization using the robust multi-array analysis (RMA) method [24]. The correlation between the two conditions was plotted on a scatter diagram. The data quality was further investigated using principal component analysis (PCA) method [25,26]. Replicate data was organized in hierarchical clustering by both individual samples as well as grouped data. A t-test filter was used to determine which genes are significantly differentially expressed and to exclude all probe sets with differential expression t-test P-values of less than 0.05.

\subsection{Real Time PCR Procedure}

Real-time PCR was performed using the $\mathrm{MyiQ}^{\mathrm{TM}}$ single-colour real-time PCR detection system (Bio-Rad, UK) and SYBER ${ }^{\circledR}$ Green PCR Master Mix (Applied Biosystem, USA). For each real-time PCR reaction, the following reaction mix was prepared and used: SYBER $\AA$ Green PCR Master Mix (12.5 $\mu \mathrm{l})$, the forward and reverse primers of the target gene ( $1 \mu \mathrm{l}$ each), the cDNA template $(1 \mu \mathrm{l})$ and the mixture was brought to $25 \mu \mathrm{l}$ by adding nuclease-free water $(9.5 \mu \mathrm{l})$. The reaction mixture was then transferred into an optical 96-well reaction plate (Applied Biosystem). Each well of the reaction plate was also supplied with $25 \mu \mathrm{l}$ of the appropriate PCR master mix. Each well was tightly covered using specific optical caps. The highly expressed housekeeping protein, GAPDH, was used as an endogenous control. The plate was then placed into the real-time PCR machine. 
Real-time PCR was performed using specific forward and reverse primers for each cDNA target sequence. The annealing temperature for each target primer set was initially optimized using the cDNA template, synthesized from the universal human reference RNA (Stratagene, UK) which composed of total RNA isolated from 10 cell lines representing different human tissues which were chosen to ensure a standard broad coverage of human genes. The real-time PCR was performed under the following cycling conditions: $94^{\circ} \mathrm{C}$ for 3 minutes, followed by denaturing at $94^{\circ} \mathrm{C}$ for 15 seconds, annealing (gradient) of $55^{\circ} \mathrm{C}$ to $63^{\circ} \mathrm{C}$ for 30 seconds, followed by $72^{\circ} \mathrm{C}$ for 15 seconds; this was repeated for 40 cycles.

Real-time PCR data and the differences between samples and controls were calculated using the Genex database software based on the comparative $(\Delta \Delta \mathrm{Ct})$ equitation method [27] to calculate relative quantities of a nucleic acid sequence. The $\mathrm{Ct}$ is the threshold cycle during which a reaction emits the threshold level of fluorescence. The detectable amount of fluorescence when a signal is significantly greater than background is known as the threshold. Data was normalized to the corresponding values of an endogenous control GAPDH.

\section{Results}

\subsection{The Quality of Total RNA}

\begin{tabular}{|c|c|c|c|c|}
\hline 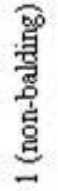 & 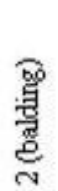 & 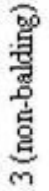 & 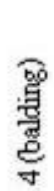 & 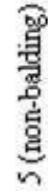 \\
\hline 旁 & 总 & 总 & $\underset{\substack{\text { 营 } \\
\text { 总 }}}{ }$ & 总 \\
\hline
\end{tabular}

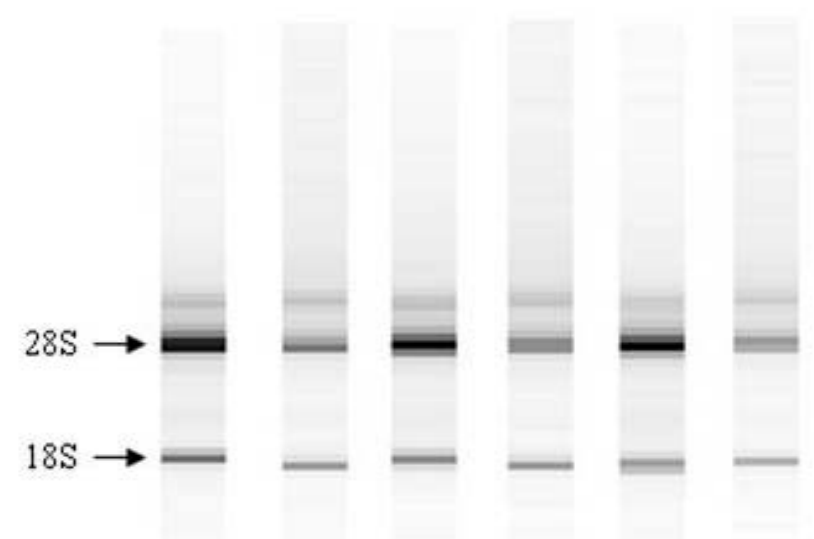

Figure 1. Electrophoretic separation of total RNA. RNA from balding samples $(n=3)$ and non-balding samples $(n=3)$ were evaluated using the Agilent 2100 Bioanalyzer. The rRNA bands (28S and 18S) exhibited 2:1 ratio and are clearly visible in the total RNA gels

The total RNA quality and purity of the six RNA samples from the three matched pairs of samples of balding and non-balding anagen hair follicles were evaluated using the Agilent 2100 Bioanalyzer (Agilent technologies). The results for all 6 samples showed clear bands with much stronger bands for 28S than 18S (Figure 1 ), with the $28 \mathrm{~S}$ rRNA band being approximately twice as intense as the 18S rRNA band. This is a good indication that the RNA is intact [28]. Non-balding samples gave stronger bands than those from balding follicles. Electropherograms (Figure 2) showed high quality RNA had been prepared for all the follicle samples for the following reasons: there are clear $28 \mathrm{~S}$ and $18 \mathrm{~S}$ peaks, the noise between the peaks is very low with minimal low molecular weight noise and the ratios are close to two.
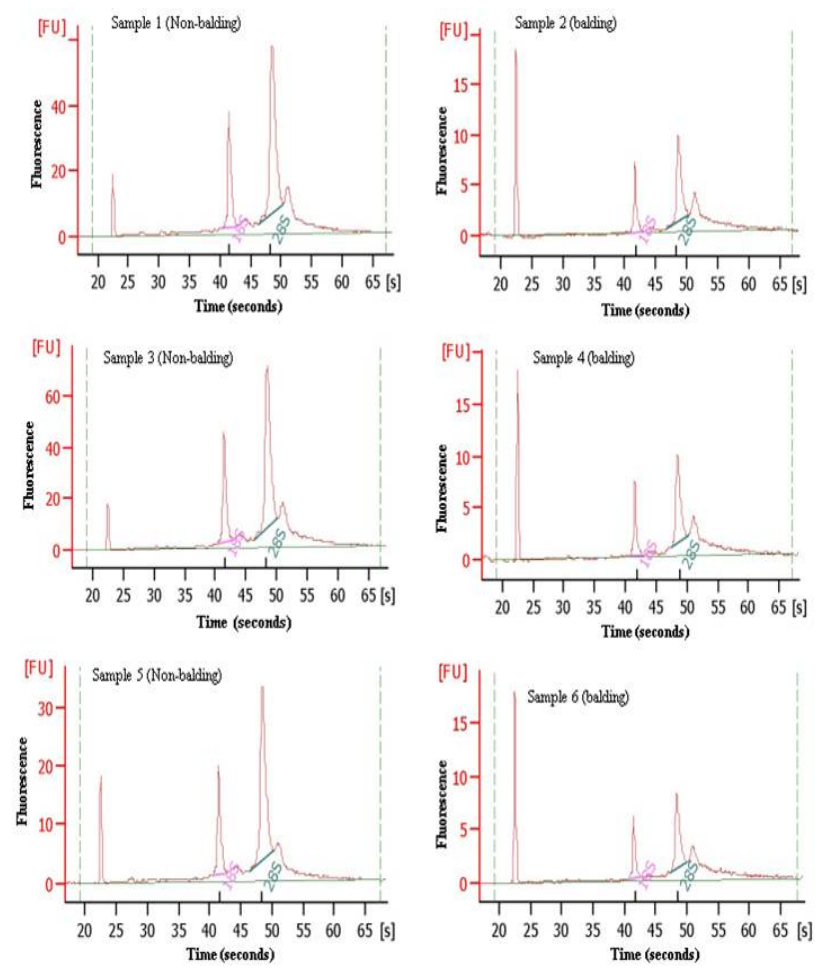

Figure 2. Electropherogram of total RNA samples. RNA obtained from balding $(n=3)$ and normal samples $(n=3)$ were evaluated using the Agilent Bioanalyzer. The graphs show high quality RNA due to presence of clear $28 \mathrm{~S}$ and $18 \mathrm{~S}$ peaks, and the noise between the peaks is very low, with minimal low molecular weight noise

\subsection{Microarray Data Analysis}

Data normalization: The difference in gene expression between balding and non-balding hair follicles in individuals with androgenetic alopecia was investigated using DNA microarray analysis. Initially, the microarray data were assessed for quality and overall differences between the two groups of matched non-balding and balding follicles. The microarray fluorescence intensity values were normalized using the Robust Multi-array Analysis (RMA) method [24]. The normalization process aims to remove certain systematic biases from microarray data [29]. To better display this large range of values and to ensure a more even representation of data, these values were transformed to log signal intensities rather than absolute signal intensities [30].

Correlation between grouped data: Since the relationship between two variables is described by their correlation, correlation analysis of the normalized fluorescence intensity values of each gene by all balding and all non-balding follicles was carried out. A scatter diagram has been used as one of the tools of quality control to check the quality of these data [31]. The graph in (Figure 3) gives a clue that the two variables are related and how they move together. This plot showed the correlation between the gene expression of balding samples $(n=3)$ and non-balding ones $(n=3)$. The results 
showed that the correlation coefficient equals (- 0.74) indicating there is a negative correlation $(\mathrm{P}<0.05)$ in gene expression between the balding and non-balding samples. The correlation curve on the plot indicates that the gene expression pattern follows a downward slope and it moves down and to the right from a high-value on the $y$-axis down to a high-value on the x-axis. In other word, when the balding sample has high fluorescence associated with expression of one gene, then the non-balding sample is tending to have a low amount of fluorescence, i.e binding or expression. In addition, the reverse pattern also occurs with high fluorescence in a non-balding sample corresponding to low expression in a balding one.

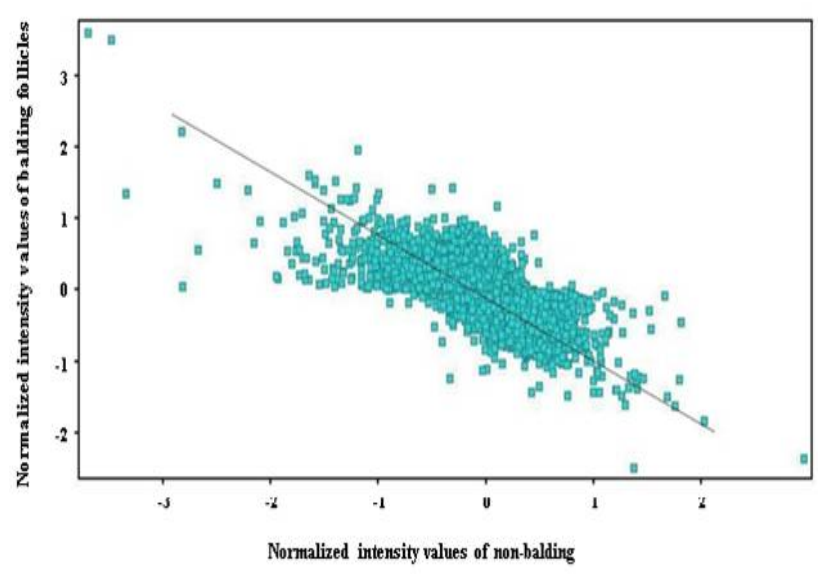

Figure 3. Scatter plot shows the correlation of gene expression between balding $(n=3)$ and non-balding follicles $(n=3)$. The correlation curve shows that gene expression follows a downward slope indicating that the pattern of gene expression is running in a band from upper left to lower right. The correlation coefficient (r) equals -0.74 indicating there is a negative correlation $(\mathrm{P}<0.05)$ in gene expression between the balding group and non-balding one

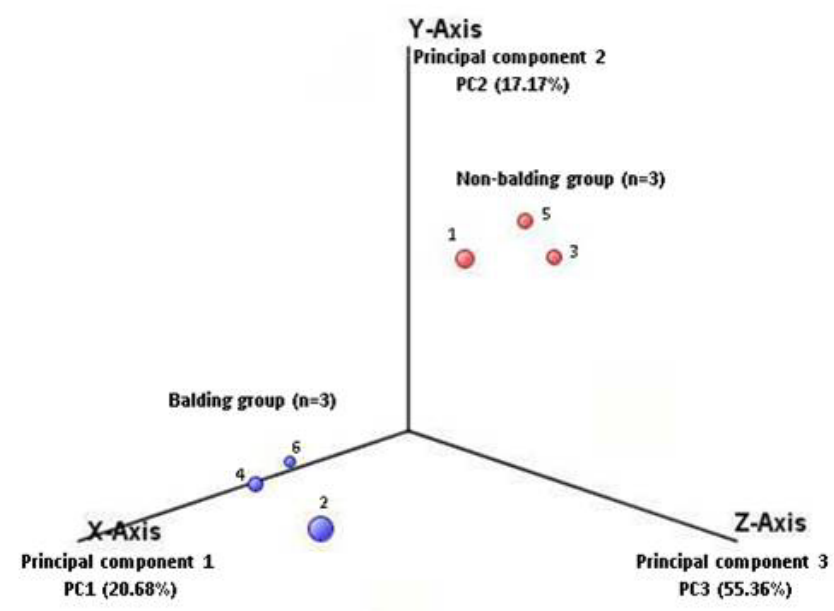

Figure 4. Principal components analysis (PCA) shows the discrimination of balding and non-balding samples. Three-dimensional graph, PCA analysis, shows that the experimental samples separated into two distinct groups, balding (blue dots) and non-balding (red dots). PC1, PC2 and PC3 are plotted on the $\mathrm{x}, \mathrm{y}$ and $\mathrm{z}$ axes respectively. PC1 and PC2 indicate $20.68 \%$ and $17.17 \%$ variation respectively within the same group, whereas PC3 indicates $55.36 \%$ variation in the total gene expression

Principal component analysis (PCA): This test provides a roadmap for reducing a complex data set to a lower dimension $[25,26]$. The three dimensional graph
(3D) in (Figure 4) shows each sample discrimination and shows clear differences between balding and non-balding follicles. Each sample demonstrated variations from each of the others. However, the balding group is separated distinctly from the non-balding group. The PC1, PC2 and PC3 are plotted on the $\mathrm{x}, \mathrm{y}$ and $\mathrm{z}$ axes respectively. PC1 and PC2 indicate $20.68 \%$ and $17.17 \%$ variations respectively within the same group, whereas PC3 indicate $55.36 \%$ variation when all samples are grouped together. This denotes that there are differences in gene expression between balding and non-balding follicle samples.

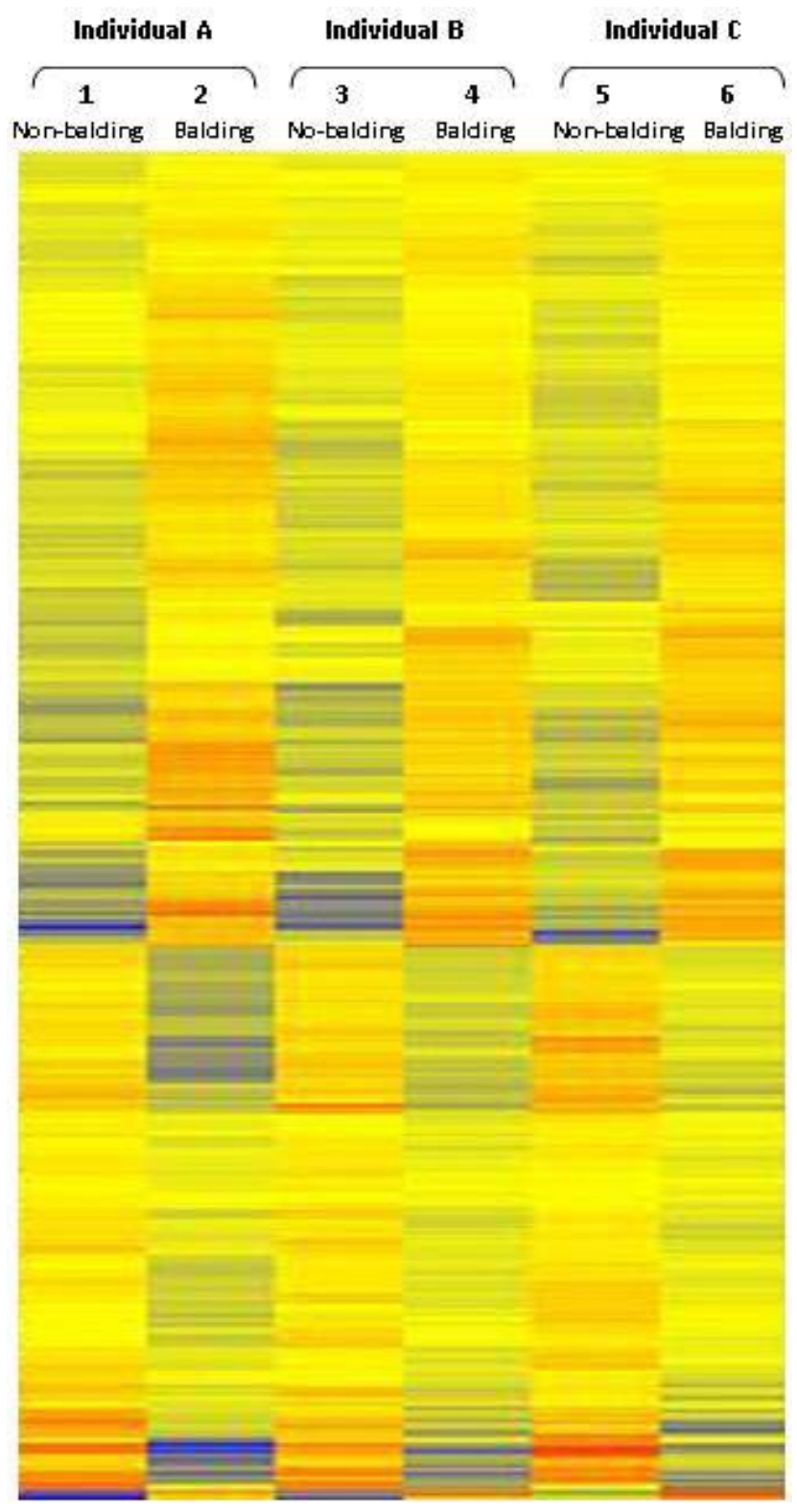

Figure 5. A comparison of the gene expression profile in individual balding and non-balding follicle samples from androgenetic alopecia men using a microarray profiling approach. Hierarchical clustering diagram showing individual expression patterns for balding samples (2, 4, 6 ) versus non-balding ones $(1,3,5)$. The diagram shows clear differences in gene expression between the two conditions in each individual

Sample clustering: To obtain an overall view of the similarities and differences between the non-balding and balding hair follicles, gene clusters were compared in each individual sample. Genes were organized into balding versus non-balding follicles by both individual samples as well as grouped samples. Genes that have the most similar expression profiles were clustered together and arranged 
based on similarity in pattern of gene expression [32]. The hierarchical clustering analysis showed a clear variability in gene expression in each individual though there were obvious pattern of similarities between the three nonbalding and three balding samples (Figure 5). When the samples were combined into two groups, balding and nonbalding, the clustering analysis showed that gene expressions were segregated into discrete clusters in the balding group compared to the control.

Statistical analysis: statistically based method, the ttest, was used to extract the meanings of the microarray experimental results to determine which genes were significantly differentially expressed, and to assess the associated uncertainty. It takes the variability of gene expression into account on a gene-per-gene basis. After applying the t-test, a total of 2,481 genes were differentially expressed in balding follicles, out of the 28,869 genes on the microarray gene chip, and showed a significant change in gene expression with p-values of less than 0.05. Analysis of the gene list showed that 1,462 genes were up-regulated and 1,019 genes were downregulated in balding scalp. When fold change filter was applied, a total of 370 genes out of 2,481 genes were differentially expressed $(\mathrm{P}<0.05)$ in balding follicles by more than 1.5 fold, 203 of those genes were up-regulated and 167 genes were down-regulated. However, there is no associated value of fold change that can indicate the level of confidence in the designation of genes as differentially expressed or not differentially expressed [33], though it is frequently used as an easy measure of difference.

\subsection{Comparison of the Expression of Keratin and Keratin Associated Protein Genes}

Since non-balding scalp follicles are larger and produce more hair than those showing some miniaturization, the expression of the keratin genes and keratin associated protein genes in balding hair follicle samples from three men with androgenetic alopecia was compared to those in their non-balding follicles. The results revealed that the expression levels of ten keratin genes and eight keratin associated protein genes were significantly downregulated in balding follicles compared to non-balding ones (Figure 6B, C).

\subsection{Comparison of the Gene Expression for some Potential Paracrine Factors}

The widely accepted mechanism of androgen action involves the stimulation of androgen receptors in the dermal papilla which alter the production of paracrine factors which regulate other cells in the follicle [18,19]. Several paracrine factors have been implicated in androgen effects on hair follicles and in the regulation of hair growth. Therefore, the expression of these factors was investigated. Results showed that balding hair follicles expressed lower levels of some possible stimulatory paracrine factors such as IGF-I, SCF, IGFBP3, and VEGF, suggesting their possible role in producing large hair follicles and hair follicles maintenance. In addition, some possible inhibitory factors were significantly increased in balding follicles such as TGFß-1, IL-1ß, IL-1 $\alpha$, and IL-6 suggesting they may be involved in hair follicles miniaturization under the influence of androgens (Figure 6A).
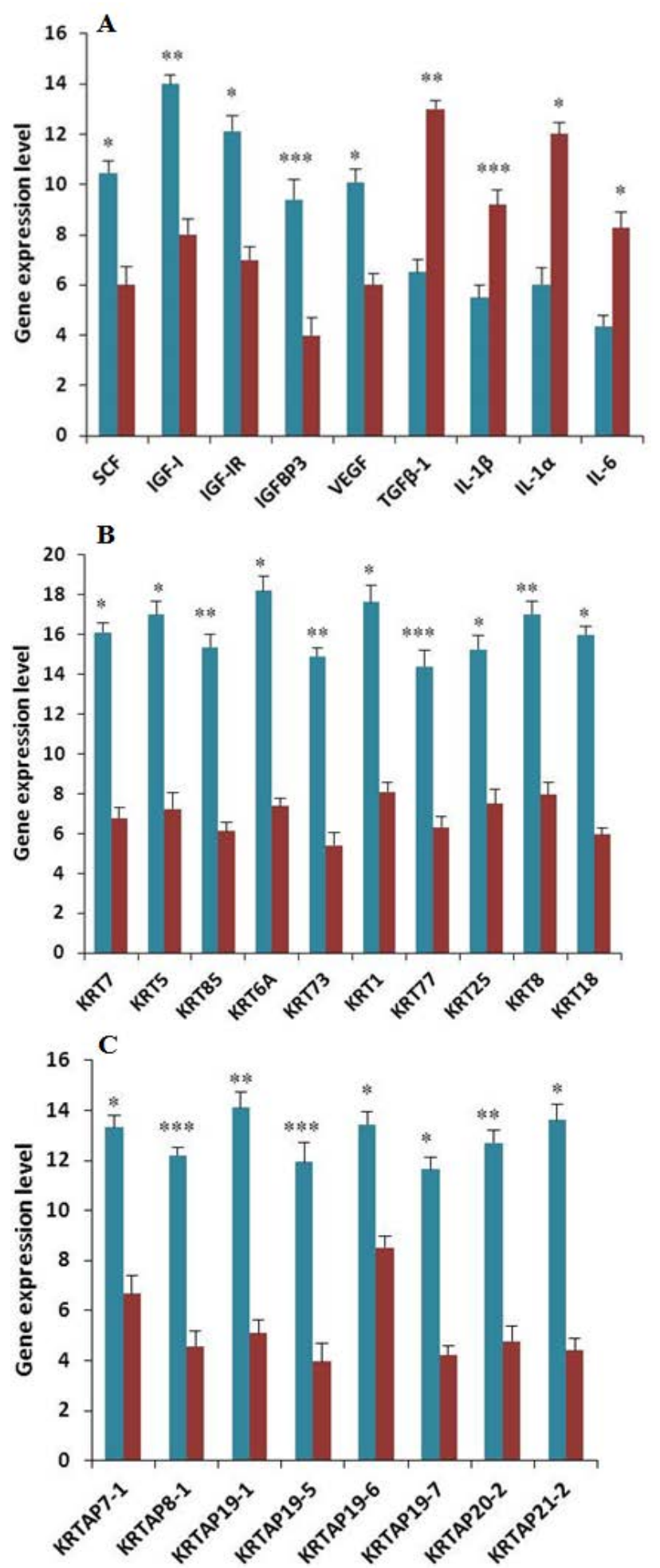

Figure 6. Comparison of the expression levels for some potential paracrine factor genes (A), Keratin genes (B), and keratin-related protein genes (C) in normal (blue) and androgenetic alopecia (brown) hair follicles. The bar diagrams show the quantitative real-time PCR expression pattern of the selected genes from microarray data. Gene expression of individual samples was normalized to GAPDH. The overall validation data show the same trend obtained from microarray analysis. Data are the mean values \pm SEM from three different individuals in both conditions. $(* \mathrm{P}<0.05, * * \mathrm{P}<0.01$, $* * * \mathrm{P}<0.001)$

\section{Discussion}


The role of paracrine factors produced by dermal papilla cells in androgen-dependent hair follicles has been the focus of much research since they are believed to be important in determining the type of hair produced [19,34]. The alteration of the size of the hair produced by a hair follicle, while at the same time maintaining many processes involved in hair growth and the hair cycle, probably requires a number of paracrine factors, some of them are inhibitory and others stimulatory. Androgens are the main known key regulator responsible for changing the type of hair produced by a hair follicle [35], stimulating enlarged follicles producing larger terminal hair in many areas after puberty, while causing reduction in follicle size on the scalp resulting in androgenetic alopecia. Therefore, having established a molecular biological approach to investigate paracrine factors in non-balding scalp follicles, this was extended to investigate how androgens alter gene expression in target follicles to change the type of hair produced. In this study, the focus was on comparing the gene expression in isolated non-balding and androgenetic alopecia hair follicles and determining whether there are significant differences between them using two comparative methods, DNA microarray analysis and quantitative real-time PCR. To maximize the likelihood of obtaining meaningful results, the comparisons were carried out using matched pairs of non-balding and balding follicles from the same men with androgenetic alopecia.

The hair keratins are the cytoplasmic intermediate filaments which form the main structural proteins of mammalian hair. They belong to a multi-gene family which consists of genes that are expressed in different type of epithelia [36]. Since non-balding scalp follicles are larger and produce more hair than those of balding scalp, the expression of the keratin genes were investigated. The results obtained from data analysis showed that ten keratin genes were significantly down-regulated in balding follicles compared to non-balding follicles. This would be expected as balding follicles produce much smaller hairs than non-balding ones and suggest that these decreased levels of keratin genes in androgen-sensitive follicles of balding scalp may occur under the influence of androgen. Whether this is direct regulation or indirect via paracrine factors from the dermal papilla is not known as yet. Reference [37] observed that keratin hHa7 was expressed in medullary cells of all types of male and female sexual hairs including beard, axillary and pubic hairs, but not in occipital terminal hairs. They also reported its expression in beard and temple vellus hair follicles. In addition, they demonstrated the expression of androgen receptor in beard hair follicles, and demonstrated the specific binding of the androgen receptor to all three putative hHa7 androgen receptor-binding elements, suggesting this type of keratin may be directly regulated by androgens.

The investigation was continued to examine the hypothesis that transforming growth factor- $\$ 1$ (TGF- $ß 1$ ) is a paracrine factor produced by dermal papilla cells and is involved in altering the size of hair follicles during androgenetic alopecia. TGF-ß1 has been observed in organ culture as a strong inhibitor factor of human hair growth [38]. Androgens induced the production of TGF$ß 1$ by balding dermal papilla cells in vitro $[39,40]$. TGF$\beta 1$ has also been implicated in the control of catagen. Premature catagen was induced when TGF- $\beta 1$ was injected into the back skin of mice [41] and a suppressor of TGF- $\beta 1$ delayed the progression of catagen in mice [42]. Androgens also stimulated balding cultured dermal papilla cells to produce TGF-ß2 [43] which is associated with the transition from anagen to catagen in human hair follicles in vitro [44]. Therefore, androgen stimulation of dermal papilla production of TGF- $\beta$ could shorten anagen. Another study showed that cultured balding dermal papilla cells have the ability to produce inhibitory autocrine factors [45]. The results of our study showed that the expression level of TGF-ß1 was significantly greater $(\mathrm{P}<0.01)$ in androgen-inhibited scalp hair follicles than in those from non-balding scalp. This supports the earlier view that androgen may induce the production of TGF-ß1 in balding scalp follicles which may work as an inhibitory factor during androgenetic alopecia causing gradual formation of miniaturized follicles. Importantly, this also validates the microarray results.

Stem cell factor (SCF) is known to play a role in the development of epidermal [46,47] and hair pigmentation $[48,49]$. Cultured dermal papilla cells derived from beard, balding and non-balding scalp secrete SCF $[35,50]$. Since the SCF receptor, c-kit, is expressed in scalp hair follicle melanocytes [51], this suggests that dermal papilla cells produce SCF to regulate follicular melanocytes and therefore alter hair pigmentation. Dermal papilla cells from beard follicles, which respond to androgen by producing darker hair in vivo, produce more SCF than those derived from non-balding scalp, which is androgeninsensitive [50]. In contrast, cultured cells from balding follicles, which respond to androgens by forming smaller paler hairs, secreted less SCF [35]. This suggests that the production of SCF may be increased in beard hair follicles and reduced in balding ones under the influence of androgen, leading to formation of differently coloured hairs. This concur with the results of this investigation which showed a significant decrease $(\mathrm{P}<0.05)$ in the expression level of SCF in balding scalp follicles compared to the control. These observations make SCF a good candidate as a paracrine factor produced by dermal papilla cells and controlled by androgens.

Insulin-like growth factor-I (IGF-I) was also investigated in this study as a possible paracrine factor implicated in androgen-regulation of hair follicle growth. IGF-I is a potent stimulator mitogen that has been shown to maintain anagen scalp hair follicles at different physiological concentrations in vitro [52], stimulate the proliferation of human skin keratinocytes in vitro [53,54]. Abnormal patterns of hair growth and differentiation have been observed when IGF-I actions were blocked in the IGF-I receptor deficient mouse [55]. Previously, reference [56] showed that the production of IGF-I was increased in response to androgens in cultured beard dermal papilla cells in vitro. They also observed that androgens induced the proliferation of outer root sheath cells when cocultured with dermal papilla cells, but this stimulatory effect was stopped when IGF-I was blocked using specific antibodies, indicating IGF-I as an androgen-regulated stimulator of hair growth in beard follicles. Data analysis of androgenetic alopecia follicles revealed that the expression of IGF-I was significantly $(\mathrm{P}<0.01)$ downregulated in balding scalp follicles compared to the normal follicles, suggesting that this reduction may occur under the effect of androgens. We also found that the expression 
of insulin-like growth factor-I receptor (IGF-IR) was significantly reduced $(\mathrm{P}<0.05)$ in isolated balding follicles compared with the control follicles. The stimulatory action of IGF-I can be mediated by specific binding protein such as IGFBP3, which induces the cellular response to IGF-I, as its binding to the cell surface leading to increased chances of receptor binding [57,58]. In this study, a dramatic decrease $(\mathrm{P}<0.001)$ in IGFBP3 expression in balding follicles was also observed.

Interleukin-1ß (IL-1ß) is a highly potent inhibitor of the growth of human hair follicles in organ culture in vitro [59]. When IL-1ß was injected intradermally into the back skin of mice, this resulted in stimulation of the apoptosis of hair bulb keratinocytes in vivo [60]. In organ culture, IL-1ß induced inhibition of human scalp hair follicles in vitro [61]. When human hair follicles were incubated with interleukin-1 $\alpha$ (IL-1 $\alpha$ ), this also led to inhibition of hair follicles growth and hair fibre production [62]. The data analysis in this investigation revealed that IL-1ß, IL- $1 \alpha$, and IL-6 were significantly up-regulated in androgenresponsive follicles of balding scalp compared to androgen-insensitive follicles of normal scalp. Recently, reference [63] found that the level of IL-6 was higher in conditioned media of balding dermal papilla cells than in those from non-balding dermal papilla cells. Following treatment with 5 $\alpha$-dihydrotestosterone, it was observed that the expression level of IL-6 was up-regulated. In addition, injection of IL-6 into the back skin of mice resulted in the induction of the catagen phase, whilst onset of the anagen phase was delayed by implantation with agarose beads containing IL-6.

Vascular endothelial growth factor (VEGF) was also investigated due to its possible role as a modulator of angiogenesis during the hair growth cycle and during hair size changes. Anagen terminal hair follicles have a good vascular system, suggesting microvascular angiogenesis may occur at an early stage of every new anagen phase [64]. Cultured dermal papilla cells were observed to express and secrete VEGF [65,66,67]. The expression of VEGF has been found at low levels in catagen and telogen scalp dermal papilla cells using fluorescent in situ hybridization and confocal laser microscopy [68]. This suggests that microvascular angiogenesis may occur at the beginning of every new anagen stage in the presence of VEGF. These observations support the results of our study in which the expression of VEGF was significantly reduced $(\mathrm{P}<0.05)$ in androgen-responsive follicles of balding scalp. This fits with the gradual changes in the size of androgen-responsive hair follicles, for instance during puberty, being reflected in the different size of their blood vessels [69]. The secretion of VEGF was stimulated by androgens in both rodent and human androgensensitive prostate cancer [70]. In patients undergoing androgen deprivation therapy for prostate cancer, the levels of VEGF were decreased compared to its level prior to treatment [71]. Based on these observations, VEGF secretion seems to be regulated by androgen in prostate, suggesting VEGF to be a potential paracrine factor involved in androgen-modulation of hair follicles.

These findings increase our understanding of androgen action in human hair follicles; this could lead to better treatment for hair disorders. Drugs which may control the levels of these factors could stimulate better hair growth in alopecia. For example, Bimatoprost has recently been shown to stimulate eyelashes growth in vivo, human scalp hair growth in organ culture, and mouse pelage hair growth in vivo [72]. This suggests that these effects are due to binding of bimatoprost to its specific receptors on the plasma membrane of dermal papilla cells. This probably stimulates intracellular signaling pathways, which induce alteration in the gene expression of paracrine signals and their extracellular release. Some of them would leave the dermal papilla to induce the keratinocytes and melanocytes to produce increased hair growth and pigmentation.

Stimulatory paracrine factors have been found to induce hair growth when they are administered externally as discussed earlier. Due to their large molecular sizes and hydrophilic to penetrate the skin lipid barrier, systemic or local injections of these factors have been successfully applied. More preferable drug delivery systems of the growth factors to the hair follicle can be achieved by encapsulation of the growth factors in liposomes or by specific gene transfer encoding the growth factors.

\section{Conclusion}

The data provided in this study support the view that androgens may exert their effect on the hair follicle via its dermal papilla cells altering their production of paracrine factors, some of which are stimulatory and some of which are inhibitory. It is clear from the microarray analysis that the changes are not due to a simple switch on or off of a single factor or factors, but rather involve modulation of a range of factors. It is not surprising that this mechanism is complex, since the hair follicle is a complicated organ involving a range of cell types and regressive and regenerative processes during the hair cycle. All these processes need to be maintained to keep producing hairs even if the type, size and colour of the hair produced is altered due to androgen influence. These factors may target different follicular components resulting in changes in the type of hair produced. An equilibration between these stimulatory and inhibitory factors is required for hair follicle maintenance and normal hair production. Disruption of this balance may lead to disorders of hair growth such as androgenetic alopecia and hirsutism. Better understanding of the roles of these factors in androgen-regulating hair growth could lead to better treatments of hair disorders.

\section{References}

[1] Thomas, J. (2005). Androgenetic alopecia-Current status. Indian J Dermatol 50, 179-90.

[2] Messenger, A. G., and Sinclair, R. (2006). Follicular miniaturization in female pattern hair loss: clinicopathological correlations. Br J Dermatol 155, 926-930.

[3] Randall, V. A. (2005). Physiology and pathophysiology of androgenetic alopecia, In Endocrinology, L. J. Degroot, and Jameson, J.L., ed. (Philadelphia: W B Saunders Co.), pp. 32953309.

[4] Randall, V. A. (2007). Hormonal regulation of hair follicles exhibits a biological paradox. Semin Cell Dev Biol 18, 274-85.

[5] Courtois, M., Loussouarn, G., Hourseau, C., Grollier J. F. (1994). Hair cycle and alopecia. Skin Pharmacol 7, 84-9.

[6] Hamilton, J. B. (1960). Effect of castration in adolescent and young adult males upon further changes in the proportions of bare and hairy scalp. J Clin Endocrinol Metab 20, 1309-1318. 
[7] Hamilton, J. B. (1942). Male hormone stimulation is a prerequisite and an incitant in common baldness. Am J Anat 71, 451-481.

[8] McPhaul, M. J. (2004). Androgen receptors and androgen insensitivity syndromes, In Endocrinology, L. J. Degroot, and Jameson, J.L., ed. (Philadelphia: W B Saunders Co).

[9] Phillipou, G., and Kirk, J. (1981). Significance of steroid measurements in male pattern alopecia. Clin Exp Dermatol 6, 5356.

[10] Pitts, R. L. (1987). Serum elevation of dehydroepiandrosterone sulfate associated with male pattern baldness in young men. $J$ Am Acad Dermatol 16, 571-573.

[11] Birch, M. P., and Messenger, A. G. (2001). Genetic factors predispose to balding and non-balding in men. Eur J Dermatol 11, 309-314.

[12] Nyholt, D. R., Gillespie, N. A., Heath, A. C., and Martin, N. G. (2003). Genetic Basis of Male Pattern Baldness. J Invest Dermatol 121, 1561-1564.

[13] Bergfeld, W. F. (1955). Androgenetic alopecia: An autosomal dominant disorder. Am J Med 98, 955-985.

[14] Ellis, J. A., and Harrap, S. B. (2001). The genetics of androgenetic alopecia. Clin Dermatol 19, 149-154.

[15] Prodi, D. A., Pirastu, N., Maninchedda, G., Sassu, A., Picciau, A., Palmas, M. A., Mossa, A., Persico, I., Adamo, M., Angius, A., and Pirastu, M. (2008). EDA2R is associated with androgenetic alopecia. J Invest Dermatol 128, 2268-2270.

[16] Hillmer, A. M., Brockschmidt, F. F., Hanneken, S., Eigelshoven, S., Steffens, M., Flaquer, A., Herms, S., Becker, T., Kortum, A. K., and Nyholt, D. R. (2008). Susceptibility variants for male-pattern baldness on chromosome 20p11. Nat Genet 40, 1279-1281.

[17] Richards, J. B., Yuan, X., Geller, F., Waterworth, D., Bataille, V., Glass, D., Song, K., Waeber, G., Vollenweider, P., Aben, K. K., et al. (2008). Male-pattern baldness susceptibility locus at 20p11. Nat Genet 40, 1282-1284.

[18] Randall, V. A. (1994). Androgens and human hair growth. Clin Endocrinol (Oxf) 40, 439-457.

[19] Randall, V. A. (2008). Androgens and hair growth. Dermatol Ther 21, 314-328.

[20] Blume-Peytavi, U., and Mandt, N. (2000). Signalling molecules in human hair follicle cell populations, In Hair and its disorders: biology, pathology and management, F. M. Camacho, Randall, V.A., and Price, V.H., ed. (Martin Dunitz, London), pp. 103-113.

[21] Paus, R. (2000). Control of the hair follicle growth cycle, In Hair and its disorders: biology, pathology and management, F. M. Camacho, Randall, V.A., and Price, V.H., ed. (Martin Dunitz, London), pp. 83-94.

[22] Philpott, M. (2000). The roles of growth factors in hair follicles: investigations using cultured hair follicles, In Hair and its disorders: biology, pathology and management, F. M. Camacho, Randall, V.A., and Price, V.H., ed. (Martin Dunitz, London), pp. 103-113.

[23] Hamilton, J. B. (1951). Patterned loss of hair in man; types and incidence. Ann N Y Acad Sci 53, 708-728.

[24] Irizarry, R., Hobbs, B., Collin, F., Beazer-Barclay, Y., Antonellis, J., Scherf, U., SPEED, T. (2003). Exploration, normalization, and summaries of high density oligonucleotide array probe level data. Biostatistics 4, 249-264.

[25] Komura, D., Nakamura, H., Tsutsumi, S., Aburatani, H., and Ihara, S. (2005). Multidimensional support vector machines for visualizing of gene expression data. Bioinformatics 21, 439-444.

[26] Shlens, J. (2009). A tutorial on principal component analysis. Centre for Neural Science, Salk Institute for Biological Studies. New York University, version 3, pp 1-12.

[27] Livak, K. J., Schmittgen, T. D. (2001). Analysis of relative gene expression data using real-time quantitative PCR and $\Delta \Delta \mathrm{Ct}$ method. Methods 25, 402-408.

[28] Skrypina, N. A., Timofeeva, A. V., Khaspekov, G. L., Savochkina, L. P., and Beabealashvilli, R. S. (2003). Total RNA suitable for molecular biology analysis. J Biotech 105, 1-9.

[29] Smyth, G. K., and Speed, T. P. (2003). Normalization of cDNA microarray data. Methods 31, 265-273.

[30] Quackenbush, J. (2002). Microarray data normalization and transformation. Nature Genetics Supplement 32, 496-501.

[31] Lee, E., and Park, T. (2007). Exploratory methods for checking qualityof microarray data. Bioinformation, Biomed informatics publishing group, 1, 423-428.
[32] Eisen, M. B., Spellman, P. T., Brown, P. O., and Botstein, D. (1998). Cluster analysis and display of genome-wide expression patterns. Proc. Natl. Acad. Sci. 95, 14863-14868.

[33] Cui, X., and Churchill, G. A. (2003). Statistical tests for differential expression in cDNA microarray experiments. Genome Biology 4, 210.

[34] Jahoda, C. A., Oliver, R. F., Reynolds, A. J., Forrester, J. C., Gillespie, J. W., Cserhalmi-Friedman, P. B., Christiano, A. M., and Horne, K. A. (2001). Trans-species hair growth induction by human hair follicle dermal papillae. Exp Dermatol 110, 229-237.

[35] Randall, V. A., Jenner, T. J., Hibberts, N. A., De Oliveira, I. O., and Vafaee, T. (2008). Stem cell factor/c-Kit signalling in normal and androgenetic alopecia hair follicles. J Endocrinol 197, 11-23.

[36] Powell, B. C., and Rogers, G. E. (1997). In: formation and structure of human hair, P. Jolles, H. Zahn and H. Hocker, eds. PP. 59-148, Birkhauser Verlag, Basel, Switzerland.

[37] Jave-Suarez, L., Langbein, L., Winter, H., Praetzel, S., Rogers, M., Schweizer, J. (2004). Androgen regulation of the human hair follicle: the type I hair keratin hHa7 is a direct target gene in trichocytes. J Invest Dermatol 122, 555-564.

[38] Philpott, M. P., Green, M. R., and Kealey, T. (1990). Human hair growth in vitro. J Cell Sci 97, 463-471.

[39] Inui, S., Fukuzato, Y., Nakajima, T., Yoshikawa, K., and Itami, S. (2002). Androgen-inducible TGF-beta1 from balding dermal papilla cells inhibits epithelial cell growth: a clue to understand paradoxical effects of androgen on human hair growth. Faseb $J 16$, 1967-1969.

[40] Inui, S., Fukuzato, Y., Nakajima, T., Yoshikawa, K., and Itami, S. (2003). Identification of androgen-inducible TGF-beta1 derived from dermal papilla cells as a key mediator in androgenetic alopecia. J Investig Dermatol Symp Proc 8, 69-71.

[41] Foitzik, K., Lindner, G. M., Mueller-Roever, S., Maurer, M., Botchkareva, N., Botchkareva, V., Metz, M., Hibino, T., Soma, T., Paolo dotto, G., Paus, A. (2000). Control of murine hair follicle regression (catagen) by TGF-b1 in vivo. Faseb J 14, 752-760.

[42] Tsuji, Y., Denda, S., Soma, T., Raftery, L., Momoi, T., and Hibino, T. (2003). A potential suppressor of TGF-beta delays catagen progression in hair follicles. J Investig Dermatol Symp Proc 8, 6568.

[43] Hibino, T., and Nishiyama T. (2004). Role of TGF-ß2 in the human hair cycle. J Dermatol Sci 35, 9-18.

[44] Soma, T., Tsuji, Y., and Hibino, T. (2002). Involvement of transforming growth factor-beta2 in catagen induction during the human hair cycle. J Invest Dermatol 1118, 993-7.

[45] Hamada, K., and Randall, V. A. (2006). Inhibitory autocrine factors produced by the mesenchyme-derived hair follicle dermal papilla may be a key to male pattern baldness. Br J Dermatol 154, 609-618.

[46] Williams, D. E., de Vries, P., Namen, A. E., Widmer, M. B., and Lyman, S. D. (1992). The Steel factor. Dev Biol 151, 368-376.

[47] Grichnik, J. M., Burch, J. A., Burchette, J., and Shea, C. R. (1998). The SCF/KIT pathway plays a critical role in the control of normal human melanocyte homeostasis. J Invest Dermatol 111, 233-238.

[48] Geissler, E. N., Ryan, M. A., and Housman, D. E. (1988). The dominant-white spotting (W) locus of the mouse encodes the c-kit proto-oncogene. Cell 55, 185-192.

[49] Fleischman, R. A., Saltman, D. L., Stastny, V., and Zneimer, S. (1991). Deletion of the c-kit protooncogene in the human developmental defect piebald trait. Proc Natl Acad Sci U S A 88, 10885-10889.

[50] Hibberts, N. A., Messenger, A. G., and Randall, V. A. (1996). Dermal papilla cells derived from beard hair follicles secrete more stem cell factor (SCF) in culture than scalp cells or dermal fibroblasts. Biochem Biophys Res Commun 222, 401-405.

[51] Randall, V. A., Jenner, T.J., and De Oliveira, I. (2001). The human hair follicle contains several populations of melanocytelineage cells with differential expression of three melanocytelineage markers c-kit and Bc1-2. J Invest Dermatol.

[52] Philpott, M. P., Sanders, D. A., and Kealey, T. (1994). Effects of insulin and insulin-like growth factors on cultured human hair follicles: IGF-I at physiologic concentrations is an important regulator of hair follicle growth in vitro. J Invest Dermatol 102, 857-861.

[53] Barreca, A., De Luca, M., Del Monte, P., Bondanza, S., Damonte, Cariola, G., Di Marco, E., Giordano, G., Cancedda, R., and Minuto, F. (1992). In vitro paracrine regulation of human keratinocyte growth by fibroblast-derived insulin-like growth factor. J Cell Patho 151, 262-268. 
[54] Tavakkol, A., Elder, J.T., Griffiths, C.E.M., Cooper, K.D., Talwar, H., Fisher, G.J., Keane, K.M., Foltin, S.K., and Voorhees, J.J (1992). Expression of growth hormone receptor, insulin-like growth factor 1 (IGF-1) and IGF-1 receptor mRNA and proteins in human skin. J Invest Dermatol 99, 343-349.

[55] Liu, J. P., Baker, J., Perkins, A. S., Robertson, E. J., and Efstratiadis, A. (1993). Mice carrying null mutations of the genes encoding insulin-like growth factor I (Igf-1) and type 1 IGF receptor (Igf1r). Cell 75, 59-72.

[56] Itami, S., Kurata, S., and Takayasu, S. (1995). Androgen induction of follicular epithelial cell growth is mediated via insulin-like growth factor-I from dermal papilla cells. Biochem Biophys Res Commun 212, 988-994.

[57] Conover, C.A., and Powell, D.R. (1991). Insulin-like growth factor (IGF)-binding protein-3 blocks IGF-I induced receptor down-regulation and cell desensitisation in culture bovin fibrobalsts. Endocrinol 129, 710-716.

[58] Tesch, G.H., Cornell, H.J., Herington, A.C. and Oakes, S. (1993). Effects of insulin-like growth factor binding protein complexes on human fibroblast growth. Growth Reg. 3, 151-159.

[59] Xiong, Y., and Harmon, C.S. (1997). Interleukin-1beta is differentially expressed by human dermal papilla cells in response to PC activation and is a potent inhibitor of human hair follicle growth in organ culture. $j$ interferon Cytokine Res 17, 151-7.

[60] Ruckert, R., Lindner, G., Bulfone-Paus, S., and Pause, R. (2000). High-dose proinflammatory cytokines induce apoptosis of hair bulb keratinocytes in vivo. Br J Dermatol 143, 1036-1069.

[61] Hoffmann, R., Eicheler, W., Wenzel, E., and Happle R. (1997). Interleukin-1beta-induced inhibition of hair growth in vitro is mediated by cyclic AMP. J Inves Dermatol 108, 40-42.

[62] Harmon, C.S., and Nevins, T.D. (1993). IL-1 alpha inhibits human hair follicle growth and hair fiber production in whole-organ cultures. Lymphoine Cytokine Res 12, 197-203.

[63] Kwack, M. H., Kim, M. K., Kim, J. C., Sung, Y. K. (2010). Interleukin-6 secreted from balding dermal papilla cells causes apoptosis in follicular keratinocytes and regulates hair cycling in mice. Exper Dermatol (19), 569.
[64] Montagna, W., and Van Scott, E. J. (1958). The anatomy of the hair follicle, In The biology of hair growth, W. Montagna, and Ellis, R.A., ed. (Academic Press, New York), pp. 39-64.

[65] Lachgar, S., Moukadiri, H., Jonca, F., Charveron, M., Bouhaddioui, N., Gall, Y., Bonafe, J. L., and Plouet, J. (1996). Vascular endothelial growth factor is an autocrine growth factor for hair dermal papilla cells. J Invest Dermatol 106, 17-23.

[66] Hibberts, N. A., Kato, S., Messenger, A.G., and Randall, V.A. (1996). Dermal papilla cells from human hair follicles secrete factors (e.g. VEGF) mitogenic for endothelial cells. J Invest Dermatol 106, 862.

[67] Merrick, A. E., Hibberts, N.A., Kato, S., Messenger, A.G., Thornton, M.J., and Randall, V.A. (1999). Both beard and scalp cultured dermal papilla cells express mRNA for, and secrete, VEGF but the levels are unaltered by testosterone in vitro. $J$ Invest Dermatol Sym Proc 4, 352.

[68] Lachgar, S., Charveron, M., Ceruti, I., Lagarde, J.M., Gall, Y., and Bonafe, J. L. (1996). VEGF mRNA expression in different stages of the human hair cycle: analysis by confocal laser microscopy. In: Hair research for the next Millenium, D. Van Neste, and V. A. Randall, edc. (Amsterdam: Elsevier) pp. 407-411.

[69] Montagna, W., and Ellis, R. A. (1958). The vascularity and innervation of human hair follicles. In: The biology of hair growth W.Montagna, and R. A. Ellis, eds. (London: Academic press Inc.) pp. 219-227.

[70] Joseph, I.B., Nelson, J.B., Denmeade, S.R., and Isaacs, J.T. (1997) Androgens regulate vascular endothelial growth factor content in normal and malignant prostatic tissue. Clin Cancer Res 3, 25072511.

[71] Aslan, G., Cimen, S., Yorukoglu, K., Tuna, B., Sonmez, D., Mungan, U., and Celebi, I. (2005). Vascular endothelial growth factor expression in untreated and androgen-deprived patients with prostate cancer. Pathol Res Pract 201, 593-598.

[72] Khidhir, K. G., Woodward, D. F., Farjo, N. P., Farjo, B. K., Tang, E. S., Wang, J. W., Picksley, S. M., Randall, V. A. (2013). The prostamide-related glaucoma therapy, bimatoprost, offers a novel approach for treating scalp alopecias. FASEB J 27, 557-567. 